\title{
EXPERIMENTAL AND NUMERICAL ANALYSIS OF ULTRA HIGH PERFORMANCE CONCRETE (UHPC) MEMBERS IN CASE OF FIRE
}

\author{
Matthias Siemon ${ }^{\mathrm{a}}$,Jochen Zehfuß ${ }^{\mathrm{a}}$ \\ ${ }^{\text {a }}$ Braunschweig University of Technology, Institute of Building Materials, Concrete Construction and Fire Protection \\ (iBMB), Braunschweig, Germany
}

\begin{abstract}
The research activity in progress and the advancements in concrete technology are leading to an increased use of high performance and ultra high performance concrete in structural engineering. Due to its high compressive strength and ductile behavior in combination with steel fibres, UHPC structural members can be designed as slender and light structures compared to standard concrete design. This increasingly leads to the option in architectural design to highlight the bearing capacity of the building without hiding the structural components.

In case of fire safety design a disadvantageous behavior of UHPC compared to normal strength concrete is well known and documented. The high packing density of the cement matrix is the main reason for explosive spalling behavior when exposed to fire. To avoid spalling, an appropriate amount of polypropylene fibres has to be introduced in the concrete mix design. In addition, slender and light structures are in general more sensitive to fire exposure due to the higher surface to volume ratio.

In this paper, the analysis of the thermal and mechanical material properties using experimental and numerical methods is presented. The investigations were carried out during the priority program 1182 in the research project "Theoretical and experimental determination of the high temperature behavior of ultra high performance concrete (UHPC)", funded by the German Research Foundation (DFG), see (Schmidt 2014) and (Hosser et al. 2014).

In the project the thermal properties heat conductivity, specific heat capacity and the temperature dependent density as well as the mechanical properties like the temperature dependent stress-strainrelation and thermal expansion were experimentally determined. In addition, the optimum fibre content was determined. The findings of the project were used to develop a material model and checked against experimental results on fire exposed UHPC columns using a FE model.
\end{abstract}

Keywords: UHPC, fire protection engineering, thermal properties, mechanical properties, material model, finite element model

\section{MIXTURES AND SPALLING BEHAVIOR}

For the fire behavior, two representative mixtures named M3Q (mortar) and B5Q (concrete) were investigated. The main difference between them is the amount of quartz sand and basalt aggregates, as shown in Table 1. This yields to a different spalling behavior due to the higher thermal expansion coefficient of quartzitic aggregates compared to basalt. Additionally, different amounts of PP fibres from $0.75 \mathrm{~kg} / \mathrm{m}^{3}$ up to $2.25 \mathrm{~kg} / \mathrm{m}^{3}$ were included to gain information about the minimum PP fibre content needed to avoid spalling. This was assessed in different small- and medium-scale tests without and with mechanical loading exposed with the ISO 834 standard fire curve.

In case of the medium-scale tests, concrete columns with a cross-section of $20 \mathrm{~cm} \times 20 \mathrm{~cm}$ and a height of $60 \mathrm{~cm}$ were exposed with the standard ISO 834 fire curve for $90 \mathrm{~min}$ without any mechanical load. The spalling behavior of the two concrete mixtures was investigated for different PP fibre contents and other protection measures like mineral wool insulation, plate insulation, ablation and intumescent coatings with varying thickness.

The results of the medium-scale for different PP fibre contents are shown in Fig. 1. It can be seen clearly from the diagram and the pictures that the large amount of quartz sand of M3Q has a negative effect for specimens without PP fibres when compared to B5Q. Furthermore it can be seen 
that an amount of $1.5-2.25 \mathrm{~kg} / \mathrm{m}^{3}$ PP fibres is sufficient to avoid large mass loss due to spalling for cases without mechanical load.

Table 1 Excerpt of the main components of concrete recipes for M3Q and B5Q

\begin{tabular}{|c|c|c|}
\hline Ingredients (Excerpt) & M3Q (mortar) & B5Q (concrete) \\
\hline Quartz powder & $200 \mathrm{~kg}$ & $456 \mathrm{~kg}$ \\
\hline Quartz sand 0.125/0.5 & $975 \mathrm{~kg}$ & $354 \mathrm{~kg}$ \\
\hline Basalt 2/5 & $0 \mathrm{~kg}$ & $298.5 \mathrm{~kg}$ \\
\hline Basalt $5 / 8$ & $0 \mathrm{~kg}$ & $298.5 \mathrm{~kg}$ \\
\hline Steel fibres $(\varnothing 0.19 \mathrm{~mm}, \mathrm{~L}=9 \mathrm{~mm})$ & $80 \mathrm{~kg}(1 \mathrm{Vol} .-\%)$ & $80-201 \mathrm{~kg}(1-2.5 \mathrm{Vol} .-\%)$ \\
\hline PP-fibres $(\varnothing 18 \mu \mathrm{m}, \mathrm{L}=4,6 \mathrm{~mm})$ & $0-2.25 \mathrm{~kg} / \mathrm{m}^{3}$ & $0-2.25 \mathrm{~kg} / \mathrm{m}^{3}$ \\
\hline
\end{tabular}

Additional tests with larger, reinforced and loaded specimens have shown that an amount of $2.25 \mathrm{~kg} / \mathrm{m}^{3}$ is needed to completely avoid spalling in most cases. This amount was then used for the production of the large-scale column test specimens.

More details to further spalling analysis of both mixtures are published in Schmidt 2014 and Hosser et al. 2012.
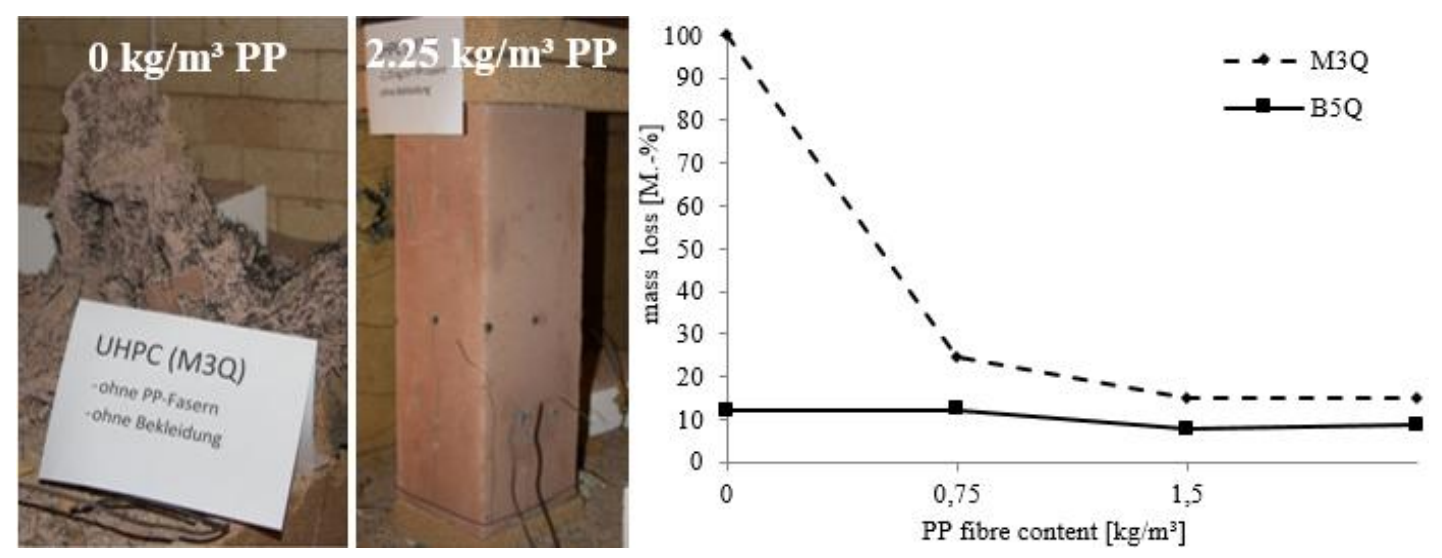

Fig. 1 Spalling in a test specimens after $90 \mathrm{~min}$ of ISO 834 fire (left) and plot of the mass loss vs. the PP fibre content (right)

\section{THERMAL MATERIAL BEHAVIOR}

For the design of fire exposed structural members, the cross-sectional temperature distribution is needed to consider the temperature induced strength decrease of reinforcement and concrete. The temperatures are calculated by numerically solving the transient Fourier's equation for two or three dimensions. Besides the initial and boundary conditions, the heat conductivity of the concrete $\lambda$, the specific heat capacity $c_{p}$ and the density $\rho$ is needed to solve the Fourier's equation. Because of the temperature induced degradation phenomena of concrete, all parameters are functions of the temperature.

The heat conductivity $\lambda$ was determined using the small-scale TPS method (Transient Plane Source) according to DIN 22007. The specific heat capacity $c_{p}$ was additionally determined using the DSC (Differential Scanning Calorimetry) method (see DIN 51007) and the density $\rho$ was measured using TGA (Thermogravimetric Analysis).

The experimental (dotted) and numerical (continuous) results are plotted in Fig. 2 for a crosssection of real scale exposed to ISO 834 fire in different depths $(10 \mathrm{~mm}-80 \mathrm{~mm})$. The experimental curves are based on the results of the four most representative tests. All tests were carried out with the same boundary conditions.

The results show that the derived constitutive functions for $\lambda, \rho$ and $c_{p}$ are capable of describing the thermal material behavior in an appropriate manner and consequently can be used as a calculation basis for numerical analysis of UHPC with comparable recipe. 


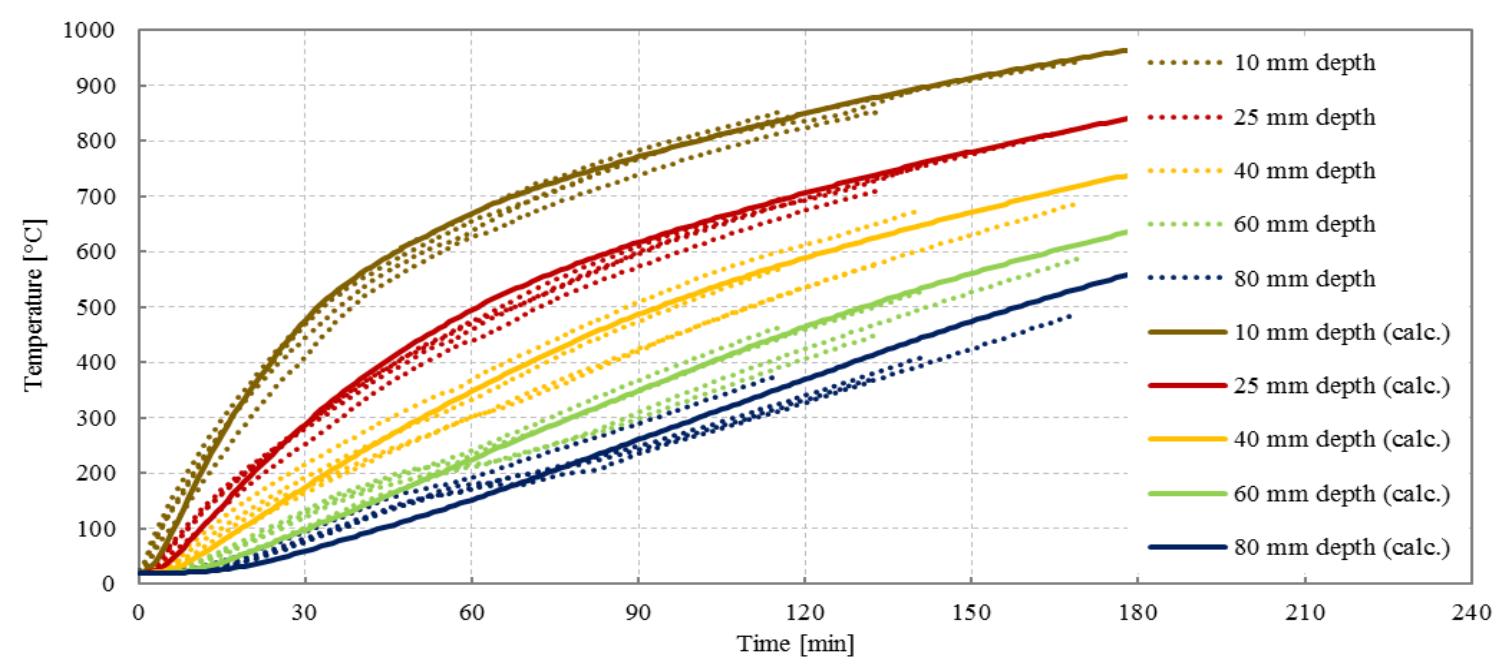

Fig. 2 Temperature development in the cross-section of real scale columns exposed to ISO 834 fire curve

\section{MECHANICAL MATERIAL BEHAVIOR OF UHPC}

The temperature dependent compression strength, the stress-strain-relationship under temperature exposure and the thermal strains were investigated using cylinder specimens with a diameter of $80 \mathrm{~mm}$ and a height of $240 \mathrm{~mm}$. The compression strength was determined using a steady-state test procedure after RILEM TC 200-HTC definitions where the specimen was heated with a heating rate of $4 \mathrm{~K} / \mathrm{min}$ to the target temperature. After a short period at this temperature (to maintain a homogenous temperature distribution in the specimen cross-section), the load was increased with a loading velocity of $0.5 \mathrm{MPa} / \mathrm{s}$ displacement-controlled until failure. The results are plotted in Fig. 3 as curve "B5Q (hot str.)".

Although the strains are measured during the steady-state tests, the test results cannot be used to derive appropriate stress-strain-relations because the transient warm creep strains are missing due to the test procedure. Therefore, transient warm or hot creep tests were conducted considering RILEM TC 129-MHT. During this test setup, a defined percentage of the $20{ }^{\circ} \mathrm{C}$ compression strength of the test specimens from $0 \%$ up to $70 \%$ was induced and kept constant. After that, the temperature was increased with the same heating rate as for the steady-state test until the specimen fails. This test setup includes the warm creep strains and delivers the thermal strains of the material for the case of $0 \%$ mechanical load. It also delivers temperature dependent compression strength values as the temperature at specimen failure can be related to the constant mechanical stress. These results are plotted in Fig. 3 as curve "B5Q (warm creep.)". Both results were used to derive a function of the temperature dependent compression strength (Fig. 3 left, curve "Calc. approach") and complete uniaxial stress-strain-relations as shown in the right graph of Fig. 3.

A more detailed description of the derivation of the stress-strain-relation and the corresponding function values are given in Richter et al. 2013 and Zehfuß \& Siemon 2015.

In the right graph, a comparison of the UHPC B5Q with a NPC C30/37 is shown, using a $20{ }^{\circ} \mathrm{C}$ compression strength of $180.65 \mathrm{~N} / \mathrm{mm}^{2}$ which was achieved by a mixture without PP fibres. Tests accompanying the real scale column tests showed that the $20^{\circ} \mathrm{C}$ compression strength of B5Q is lower (about $150-160 \mathrm{~N} / \mathrm{mm}^{2}$ ) due to the addition of $2.25 \mathrm{~kg} / \mathrm{m}^{3}$ PP fibres. As shown in Fig. 3 (left), the compression strength increases at $300{ }^{\circ} \mathrm{C}$ up to $115 \%$ of the $20^{\circ} \mathrm{C}$ value after a strength loss between $80^{\circ} \mathrm{C}$ and $150^{\circ} \mathrm{C}$. This behavior can be seen in several other publications for HPC and UHPC, e.g. Huismann 2010 and Phan \& Carino 2003. It is explained with different hypotheses considering specific $\mathrm{CSH}$ phase reactions or hydrothermal effects. In the calculation, this behavior was not considered and instead, a constant compression strength up to a temperature of $500{ }^{\circ} \mathrm{C}$ was defined. 

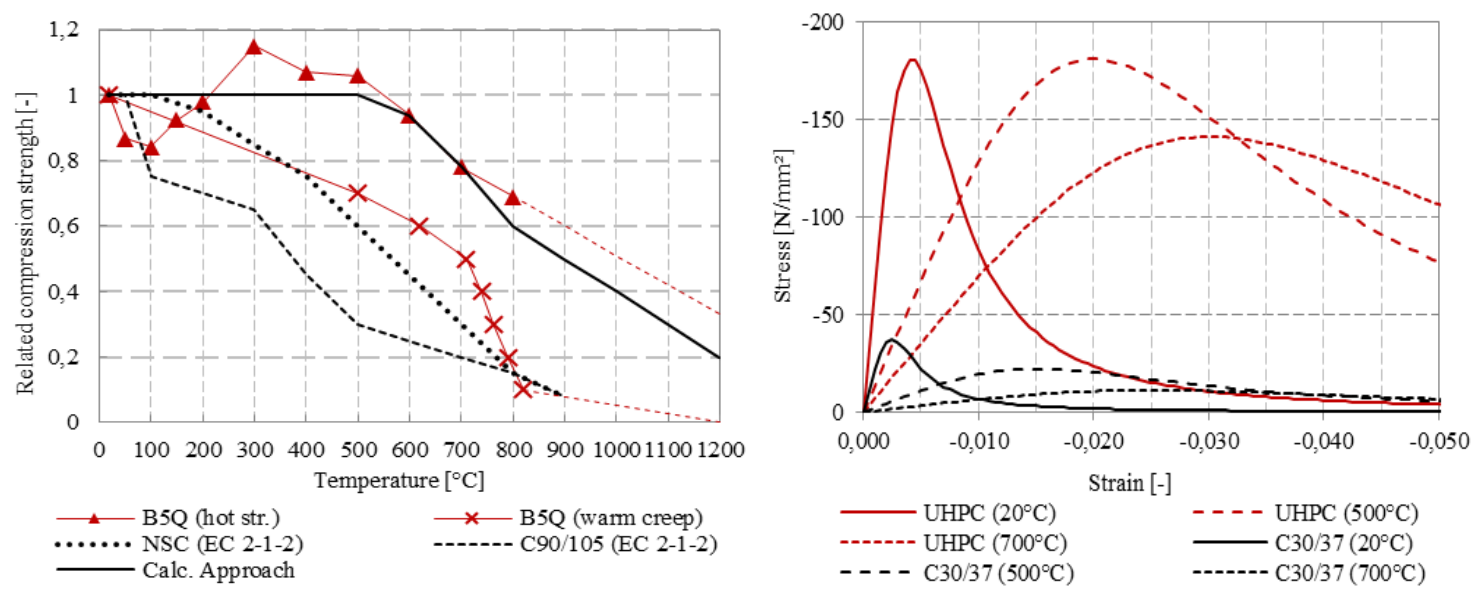

Fig. 3 Temperature dependent compression strength (left) and stress-strain-relation (right) of UHPC (B5Q)

\section{FIRE TESTS AND NUMERICAL ANALYSIS}

The columns for the real-scale fire tests acc. to ISO 834 had a cross-section of $30 \mathrm{~cm} \times 30 \mathrm{~cm}$ (all faces exposed to fire) and a length of $3.7 \mathrm{~m}$. They consisted of eight reinforcement bars of Steel B 500 with a diameter of $20 \mathrm{~mm}$. The binder reinforcement with a diameter of $10 \mathrm{~mm}$ is located each $10 \mathrm{~cm}$ (at the supports) or each $20 \mathrm{~cm}$ (in the middle of the column). The column is supported by two hinged supports on both ends which were realized by steel plates. Four reinforcement bars were lined up in the tension and compression zone orthogonal to the main bending direction. The concrete coverage was $4.5 \mathrm{~cm}$. In four tests the mechanical loading $(1200 \mathrm{kN}-1800 \mathrm{kN})$, the eccentricity $(7.5 \mathrm{~mm}-15 \mathrm{~mm})$ and the actual compression strength for each column $\left[\mathrm{N} / \mathrm{mm}^{2}\right]$ (S1: 145.5, S2: 163.7, S3: 158.5, S4: 156.6) were varied (Hosser et al. 2014).

All thermocouples were embedded in the casting phase at different heights and different sides of the columns. Displacements and the temperatures were recorded over the whole duration of the fire test. As shown in Fig. 2 the heat transfer boundary conditions defined in EN 1991 1-2 are valid for all four fire tests. Spalling was avoided by adding $2.25 \mathrm{~kg} / \mathrm{m}^{3} \mathrm{PP}$ fibres to the concrete mixture. During test S3, negligible spalling (mean depth $<10 \mathrm{~mm}$ ) was recorded at the upper part near the support.

The concrete material model, detailed in Selby \& Vecchio 1997 and utilized in this analysis, is called the total-strain-crack model. This approach was specifically designed for three-dimensional calculations of reinforced concrete components and is implemented in DIANA (DeWitte \& Wijtze 2012).

The mechanical FE model consists of three-dimensional isoparametric brick elements with quadratic shape functions (concrete volume) and bar elements embedded within the brick elements (reinforcement). In the simulations, perfect bond between reinforcement and concrete is assumed. The thermal analysis was done using a two-dimensional model of the cross-section. Due to the constant boundary conditions over the column height, the results were then extended to a threedimensional temperature field for each time step and handed over to the mechanical calculation. This separation allowed the definition of a finer mesh for the temperature calculation, considering the large temperature gradients at the beginning and at the edge areas of the columns. The influence of cracks on the temperature is neglected. The FE model accounts for geometrical nonlinear behavior.

The tension strength of the UHPC was taken into account for the numerical model using $10 \%$ of the compression strength for ambient temperature $\left(20^{\circ} \mathrm{C}\right)$ which was derived in accordance to experimental results for the UHPC mixture B5Q published in Schmidt 2014. The influence of the temperature was modelled using the definitions of EN 1992 1-2 for NPC. Experimental results of Felicetti et al. 1996 and Behnhood \& Ghandehari 2009 for HPC have shown that this assumption should be valid for UHPC as well. Due to numerical reasons, the tension strength loss is limited to $1 \%$ of the ambient strength. The stress-strain behavior was considered in accordance to EN 1992 12 with yield strength of reinforcement with mean value $543 \mathrm{~N} / \mathrm{mm}^{2}$. 


\section{$5 \quad$ RESULTS}

The calculated and test failure times (criteria acc. to EN 13501-2) are shown in Fig 6. Test S1 was stopped after $118 \mathrm{~min}$ and the column was taken as a test specimen for the investigation of the residual load capacity after fire exposure.

Considering the failure time, all results show a good compliance between the experimental and the calculated data. The experimentally determined horizontal displacement and the calculated values are plotted in Fig. 4. For the tests S2 and S4, the calculated and measured displacements are quite similar until $140 \mathrm{~min}$ for $\mathrm{S} 2$ and $115 \mathrm{~min}$ for $\mathrm{S} 4$. After that time, the calculated horizontal displacements grow rapidly and lead to failure 9 min earlier than experimentally determined. For both tests, the deviation between both curves starts at values of about $30-40 \mathrm{~mm}$.

The tests S1 and S3 show larger deviations between the calculation and the experimental values. Although S1 was stopped after 118 minutes, it can be seen that the calculation underestimates the displacement. The larger displacements for S1 can be partly explained by the lower compression strength, but not for S3 with a determined compression strength comparable to S2 and S4. Furthermore, the experimentally determined horizontal displacements of S3 and S4 as well as the failure times are quite similar despite $400 \mathrm{kN}$ difference in loading. As Richter et al. 2013 mentioned, the small difference in experimental failure time lies in the different failure mode of S3 and S4. The test S3 was carried out until stability failure at large horizontal displacements (> $120 \mathrm{~mm}$ ), whereas $\mathrm{S} 4$ was stopped after the cross-sectional resistance was reached $(\sim 70 \mathrm{~mm})$. Besides the failure time, the simulation of S3 expects lower horizontal displacements due to the lower mechanical loading.
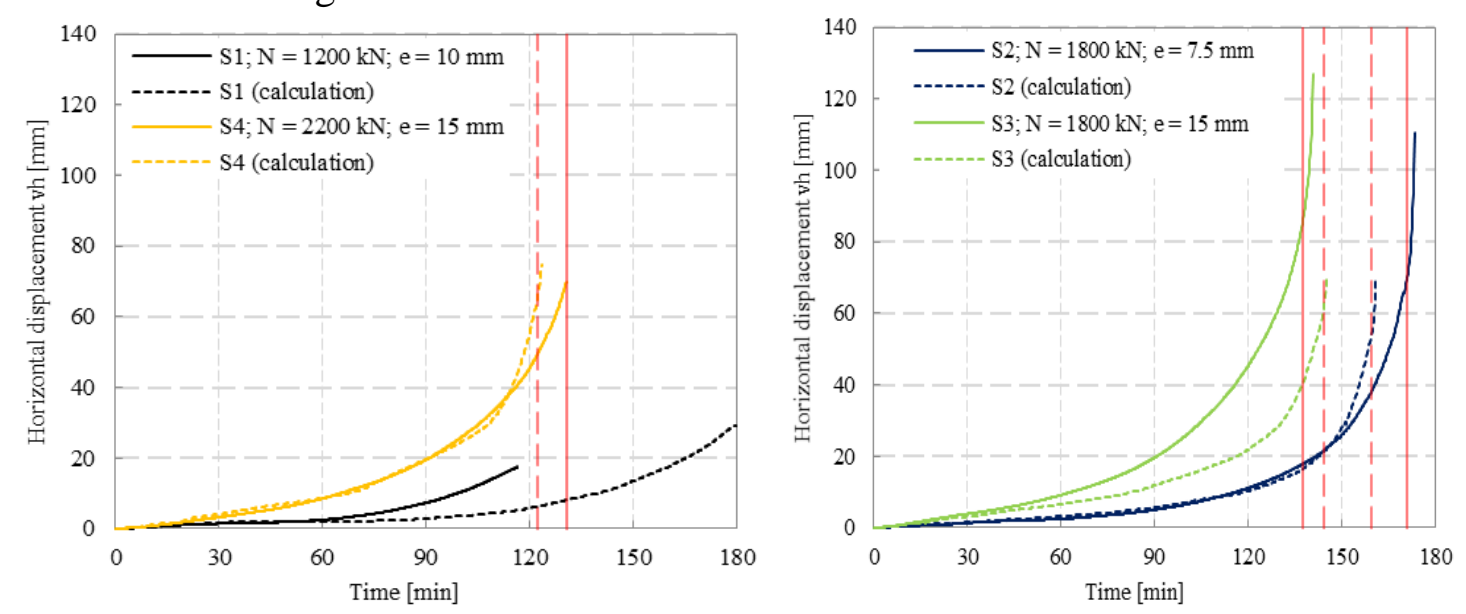

Fig. 4 Horizontal displacements of the columns S2 - S4 during fire exposure and failure times

Additional information concerning the measured and calculated vertical displacement, the rotation of the support and stress distribution in the concrete section and reinforcement is given in Zehfuß \& Siemon 2015. As a conclusion, the compliance of the measurements and the simulation is good considering the uncertainties in high temperature tests.

\section{CONCLUSIONS}

In this paper, the spalling behavior and the thermal and mechanical parameters of UHPC (mixture B5Q) are presented. An amount of $2.25 \mathrm{~kg} / \mathrm{m}^{3}$ PP fibres (Ø $\left.18 \mu \mathrm{m}, \mathrm{L}=4,6 \mathrm{~mm}\right)$ was sufficient to prevent all small- and large-scale test specimens from serious concrete spalling. The thermal analysis based on the experimentally derived values for $\lambda, \rho$ and $c_{p}$ show a good compliance with the measured values (Fig. 2) and are therefore suitable for use as a basis for a thermal analysis of UHPC with a similar recipe than the mixture B5Q.

Compared to NPC, the compression strength of the analyzed mixture B5Q remains at nearly $80 \%$ of ambient temperature strength at a temperature of $700{ }^{\circ} \mathrm{C}$, a value where NPC has only $30 \%$ compression strength left. Considering the results of the transient warm creep tests, the compression strength of $\mathrm{B} 5 \mathrm{Q}$ is at $50 \%$ ambient compression strength at $700{ }^{\circ} \mathrm{C}$. Mainly influenced by the 
basaltic aggregates and the larger amount of cement and binder, the thermal expansion of UHPC is lower than for NPC. As seen in comparison to a NPC C30/37, the strains corresponding to the maximum compression strength are much higher than for NPC.

To validate the mechanical material properties, large-scale column tests were conducted and compared to simulation results. Although there are differences in the measured and calculated values of the horizontal displacement for specific tests (S3, S1), the comparison of the failure time shows a maximum deviation of $6.9 \%$ which is a good value.

As a conclusion, the thermal and mechanical properties presented can be used for numerical simulations of UHPC structural members exposed to fire, but it has to be kept in mind that concrete mixtures not similar to B5Q can behave differently. Furthermore, in case of natural fires there might be a significant difference in material behavior during the cooling phase. Here, additional research is needed to expand the knowledge from standard fire to natural fire design.

\section{ACKNOWLEDGMENTS}

The authors would like to acknowledge the German Research Foundation (DFG) for the support of the research project 'Theoretische und experimentelle Untersuchungen zur Ermittlung und Optimierung des Brandverhaltens von ultra-hochfestem Beton' (Theoretical and experimental studies for determining and optimizing the fire behavior of ultra high performance concrete) in the priority program 1182.

\section{REFERENCES}

Behnood, A. and Ghandehari, M., 2009. Comparison of compressive and splitting tensile strength of highstrength concrete with and without polypropylene fibers heated to high temperatures. Fire Safety Journal 44(8), p. 1015-1022.

DeWitte, F. C., Wijtze, P. K., 2012. DIANA - Finite Element Analysis - User's Manual - Material Library (Release 9.4.4), Delft: TNO DIANA BV.

Felicetti, R., Gambarova, P. G., Rosati, G. P., Corsi F., Giannuzzi, G., 1996. Residual mechanical properties of high-strength concretes subjected to high-temperature cycles, in Proceedings of the International Symposium of Utilization of High-Strength/High-Performance Concrete, Paris, France, p. 579-588.

Hosser, D., Kampmeier, B., Hollmann, D., 2012. Behavior of UHPC in case of fire, in Proceedings of Hipermat $20123^{\text {rd }}$ International Symposium on UHPC and Nanotechnology for High Performance Construction Materials, 7-9 March 2012, Kassel, Germany, p. 573 - 582.

Hosser, D., Siemon, M., Kampmeier, B. Hollmann, D., Kruse, D., Deppe, B., 2014. Theoretische und experimentelle Untersuchung zur Ermittlung und Optimierung des Brandverhaltens von ultra-hochfestem Beton (UHPC), aus Nachhaltiges Bauen mit ultra-hochfestem Beton, Schriftenreihe Baustoffe und Massivbau, Kassel: university press.

Huismann, S., 2010. Materialverhalten von hochfestem Beton unter thermo-mechanischer Beanspruchung, $\mathrm{PhD}$ Thesis, Technische Universität Wien (in German).

Phan, L. T., Carino, N. J., 2003. Code Provisions for High Strength Concrete Strength-temperature relationship at elevated temperatures, Materials and Structures, 256(36), p. 91-98.

Richter, E., Zehfuß, J., Kampmeier, B., 2013. Entwicklung vereinfachter Materialgesetze in Form von temperaturabhängigen Spannungs-Dehnungs-Beziehungen für ultrahochfesten Beton. Bauphysik 35(5), p. 303 - 322 (in German).

RILEM TC 200-HTC: Mechanical concrete properties at high temperatures - modelling and applications, Part 2: Stress-strain relation. Materials and Structures, Vol. 40 (2007), S. 855 - 864; Part 10: Restraint Stress. Materials and Structures, Vol. 38 (2005), p. 913 - 919.

RILEM TC 129-MHT: Test Methods for mechanical properties of concrete at high temperatures, Part 7: Transient Creep for service and accident conditions. Materials and Structures, Vol. 31 (1998), p. 290 295.

Schmidt, M., 2014. Nachhaltiges Bauen mit ultra-hochfestem Beton: Ergebnisse des Schwerpunktprogrammes $1182=$ Sustainable building with ultra-high performance concrete. Heft 22, Kassel : Kassel university press.

Selby, R. G., Vecchio, F. J., 1997. A constitutive model for analysis of reinforced concrete solids. Canadian Journal of Civil Engineering 24, p. $460-470$.

Zehfuß, J., Siemon, M., 2015. Numerische Analyse brandbeanspruchter Stützen aus ultrahochfestem Beton (UHPC), Bautechnik, 92(5), p. 335 - 345 (in German). 